\title{
Zur köktürkischen Inschrift I E 19-21 (Tномsex).
}

In dieser Stelle wird uns gesagt: „Khan der Kirgisen (?) war Bars Bäg; ihm hatten wir den Khan-Titel und unsere jüngere Schwester gegeben, doch fiel er von uns ab und starb. Damit jedoch das Land und Wasser des Kögmän nicht herrenlos bleibe az Kyrkyz budun-yg jaratyp kältimiz süñüs-dimiz (Lücke von 4 Zeichen) jana bärtimiz".

Da nun in IN 13 erzählt wird, der Khan der Kirgisen babe zu Käl Tägin's Trauerfeierlichkeiten seine Vertreter gesandt, so ergiebt sich als Ergünzung der Lücke am Schluss von Z. 20, statt 'Tномsen's ilin, ganz unzweideutig kagan-yg (geschr. K G N G): «.....wir kamen, kämpften und gaben ihnen wieder einen Khan".

Diese Erklärung kann meine Ausführungen über balbal (cf. T'oung-pao, VII, p. 352, Anm. 3) selbstverständlich nicht beeinflussen: der gestorbene Khan wurde als balbal errichtet, während der neu eingesetzte Khan mit seinem Oberherrn in gutem Einvernehmen stand. Gerade die Stellen I N 11-13 und II S 10-12 zeigen deutlich, dass balbal mit den Trauerfeierlichkeiten Nichts zu thun hatte; denn im entgegengesetzten Falle wäre es höchst auffallend, dass bei Kül Tägin's und Bilgä Khan's Tode der »Trauermarschall" gar nicht erwähnt wird.

W. Bang.

\section{Lettre de M. W. Grube à M. G. Schlegel.}

In seiner Besprechung meiner »Sprache und Schrift der Jučen" bemerkt Herr Prof. Sehlegel, dass sub No. 57 des Glossares 没 in der Bedeutung $\gg$ Wasser" mit naandsch. muke identificirt werde, während es sub $\mathrm{N}^{\circ}$. $117 \gg$ Holz" bedeute. Da müsse ein Fehler vorlieger, da die Jučencharactere für Holz und Wasser verschieden 